\title{
IMPROVED ENERGY EFFICIENCY IN WINERIES USING DATA FROM AUDITS
}

\section{MELHORIA DA EFICIÊNCIA ENERGÉTICA EM ADEGAS UTILIZANDO DADOS DE AUDITORIAS}

\author{
Raquel Vela ${ }^{1}$, Fernando Ruiz Mazarrón ${ }^{1}$, Joaquín Fuentes-Pila ${ }^{2}$, Fátima Baptista ${ }^{3}$, Luis Leopoldo Silva ${ }^{3}$ and \\ José Luis García ${ }^{1 *}$
}

\author{
${ }^{1}$ Universidad Politécnica de Madrid, Agroforestry Engineering Department, Ciudad Universitaria s/n, 28040 Madrid, Spain. \\ ${ }^{2}$ Universidad Politécnica de Madrid, Agricultural Economics, Statistics and Business Management, Ciudad Universitaria s/n, 28040 Madrid, \\ Spain. \\ ${ }^{3}$ University of Évora, Department of Rural Engineering/ICAAM, P.O. Box 94, 7002-554 Évora, Portugal.
}

*corresponding author: Tel: +34 913365666, e-mail: joseluis.garciaf@upm.es

(Received 13.05.2016. Accepted 14.03.2017)

\section{SUMMARY}

The wine production process has a high energy demand of about 1,750 million $\mathrm{kWh}$ per year in the EU. Saving energy, responsible consumption and efficient use of energy sources are key aspects to consider for the competitiveness and viability of the sector. Therefore, the TESLA project (Transfering Energy Save Laid on Agroindustry), funded by the European Commission, has conducted 39 energy audits in wineries from four countries (Spain, France, Portugal and Italy). The information collected has allowed them to carry out a comparative analysis of energy efficiency measures through a technical-economic study, calculating the period of return on investment and performing a sensitivity analysis to determine the break-even point for each of the investments analysed. The results show that the replacement of chillers by more efficient ones, the installation of variable speed drives on pumps, the introduction of management and control measures such as the implementation of a Building Management System (BMS) and the installation of energy analysers for identification of consumption by use are the measures that have the greatest quantitative impact.

\section{RESUMO}

Na União Europeia, o consumo anual de energia associado à produção do vinho é de cerca de 1,750 $\mathrm{M}$ kWh. A poupança de energia, o consumo responsável e o uso eficiente do recurso energia são aspetos chave a considerar para a competitividade e viabilidade do sector. Deste modo, o projeto TESLA (Transferring Energy Save Laid on Agroindustry), financiado pela Comissão Europeia, realizou 39 auditorias em adegas localizadas em quatro países (Espanha, França, Portugal, Itália). A informação recolhida permitiu realizar um estudo comparativo das medidas de melhoria de eficiência energética do ponto de vista técnico-económico, através do cálculo do período de retorno do investimento e de análise de sensibilidade para determinar o ponto de equilíbrio para cada investimento analisado. Os resultados mostram que a substituição de chillers antigos por outros mais eficientes, a instalação de variadores de velocidade nas bombas e a introdução de medidas de gestão e controlo, tais como: a implementação do sistema de gestão de edifícios e a instalação de analisadores de energia que permitem a identificação do consumo por etapa, são as medidas que apresentam maior impacto do ponto de vista quantitativo.

Keywords: energy efficiency, food industry, wine.

Palavras-chave: eficiência energética, industria alimentar, vinho

\section{INTRODUCTION}

Vine-growing and wine production is an essential economic and labour intensive activity and plays a major social-economic role for many Member States and regional economies, and for the EU economy as a whole. Wine production represents approximately $10 \%$ of agricultural production in countries like
France, Italy, Austria, Portugal and Spain (CEEV, 2014).

The energy consumption in wine production in the European Union is approximately 1,750 million $\mathrm{kWh}$ per year (500 million kWh in France, 500 million $\mathrm{kWh}$ in Italy, 400 million $\mathrm{kWh}$ in Spain, and 75 million kWh in Portugal), with electricity as the main 
energy source (over 90\%) (Fuentes-Pila and García, 2014).

Given the high energy consumption that the current wine production process demands, saving energy, responsible consumption and efficient use of energy sources are key aspects to consider for the competitiveness and viability of the sector. The importance of energy efficiency and saving measures is manifested in the need to reduce the energy bill, restricting foreign energy dependence, and reduce the emission of greenhouse gases (GHGs).

In this context, many authors have focused their efforts on improving the energy efficiency of wineries through the study of the buildings used therein, to reduce consumption in air conditioning. For example, Mazarrón et al. (2012b) and Benni et al. (2013), compare the efficiency of different building designs. Other authors study a particular building design, such as aboveground wineries (Mazarrón et al., 2012a), basement constructions (Mazarrón et al., 2013), underground constructions (Mazarrón and Canas, 2008, 2009; Canas and Mazarrón, 2009; Barbaresi et al., 2014; Tinti et al., 2014, 2015).

However, the efficiency of the building design is not the only method for improving the energy efficiency of the wineries. Thus, energy savings in specific stages of the production process can be achieved, such as fermentation (Neves et al., 2013; Celorrio et al., 2015, 2016); through the design of airconditioning systems with high efficiency (Wei et al., 2014), through the incorporation of renewable energy sources (Smyth and Russell, 2009); by reduction of the infiltration rate (Hejiang and Qingxia, 2014), among others.

Sustainability and environmental aspects are also considered by several authors (Forbes and De Silva, 2012; Point et al., 2012; Pomarici et al., 2015; Iannone et al., 2016), as the economic performance of companies in the sector (Alonso and Northcote, 2010; Sellers-Rubio, 2010; Simon-Elorz et al., 2015). Other analysed aspects related to energy efficiency of the wineries have been the size distribution (Cyr et al., 2012) and the layout design (Torreggiani et al., 2014).

Although the numerous studies that analyse the energy efficiency of food industries (Martinodotnez, 2010; Gaspar et al., 2014; Lijun, 2014; Miah et al., 2015; Rodríguez-González et al., 2015), there is no evidence of any publication that focuses on wineries. Therefore, this paper analyses energy efficiency in different stages of wine production, quantifying the profitability of implementing measures for its improvement.
This work is part of the European TESLA project (Transferring Energy Save Laid on Agroindustry, IEE/12/758), performed between 2013 and 2016 (www.teslaproject.org). TESLA project was aimed to improve energy efficiency in four agribusiness sectors, specifically: wineries, olive oil mills, fruit and vegetable processing plants and animal feed mills. Nine organisations have participated: Spanish Co-ops (project leader, www.agroalimentarias.coop), Technical University of Madrid (www.upm.es), and CIRCE (www.fcirce.es) from Spain; Coop de France (www.coopdefrance.coop) and TECALIMAN (www.tecaliman.com) from France; Confagri (www.confagri.pt) and University of Évora (www.uevora.pt) from Portugal; Legacoop (www.legacoop.coop) and ENEA (www.enea.it) from Italy.

In the sector of wineries, in particular, the TESLA project has conducted 39 audits in the four countries involved (TESLA project, 2014; TESLA project, 2015). This information has been joined to the 8 energy audits and 20 energy diagnosis in wineries of Spain in a previous project (CO2OP project, 2011), also led by Spanish Co-ops. The energy diagnosis carried out were simpler studies of the installations and production process; a typical audit of the CO2OP project was performed during one month, and an energy diagnosis in only one week.

\section{MATERIAL AND METHODS}

The methodology is based on data from energy audits. From them, critical points of high consumption and potential improvement have been identified, evaluating and proposing measures to improve energy efficiency. The proposed measures are based on replacement and acquisition of equipment that is more efficient as well as improving management and control.

For a reference installation of the four countries (France, Italy, Portugal and Spain), the following general average values can be considered as a reference for the production of red wine (without ageing process), which is the most common type of production (Fuentes-Pila and García, 2014):

$\checkmark$ Size of industry, around $30,000 \mathrm{hl}$ of wine per year;

$\checkmark$ Power consumption around 330,000 kWh/year;

$\checkmark$ Ratios of electricity consumption/production and thermal consumption/production about $11 \mathrm{kWh} / \mathrm{hl}$ wine and $1 \mathrm{kWh} / \mathrm{hl}$ wine, respectively; 
Prices of electrical and thermal energy, 0.12 $€ / \mathrm{kWh}$ and $0.07 € / \mathrm{kWh}$, respectively. These values are an average considering the reference winery (it is, for red wine without ageing). They are different in each country (Fuentes-Pila and García, 2014):

- Italy, 0.14/0.15 €/kWh and 0.03/0.04 €/kWh (electrical and thermal, respectively)

- Spain, 0.12/0.13 €/kWh and 0.055/0.065 $€ / \mathrm{kWh}$

- France, 0.06/0.11 €/kWh and 0.02/0.08 $€ / \mathrm{kWh}$

- Portugal, 0.07/0.09 €/kWh and 0.06/0.08 $€ / \mathrm{kWh}$

The collected information allows one to calculate the average rates of energy consumption of a reference winery from the four European countries involved. The reference winery is a cooperative dedicated to the production of 30,000 hl/year red wine without ageing processes. The winery also includes the offices of the cooperative. The winemaking process is described in Figure 1.

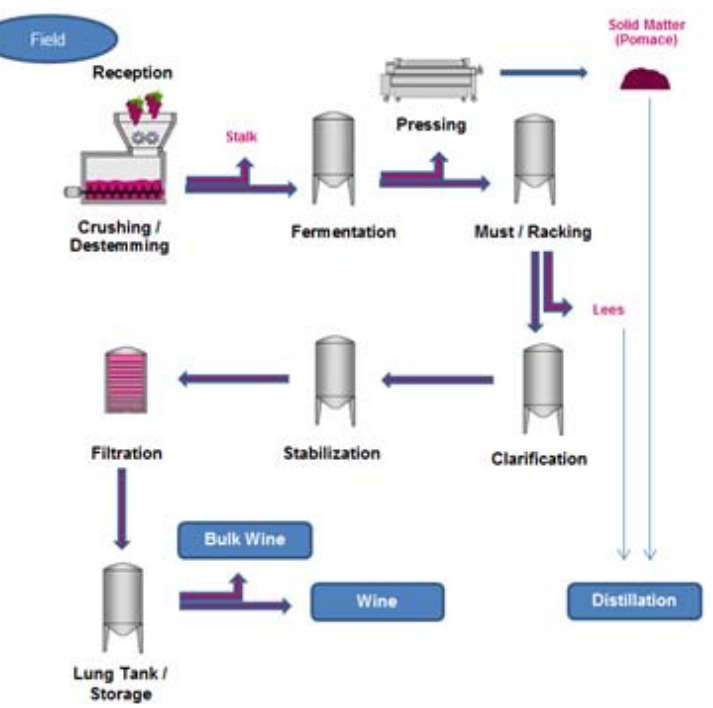

Figure 1. Process scheme of a $30.000 \mathrm{hL} /$ year red wine winery, considered reference for the four countries (Spain, France, Portugal and Italy).

Esquema do processo produtivo para uma adega que produz 30.000 hL/ano de vinho tinto, considerado como representativo nos 4 países (Espanha, França, Portugal e Itália).

An energy audit has enabled an inventory of existing equipment in the winery, identifying and characterising 296 electrical devices grouped into 63 different types. In all the analyses a reference winery of 30,000 hl/year has been used. Data from this reference winery has been profiled using information obtained from the energy audits analyses for the audited wineries, adjusting the equipment power of these wineries to the average of corresponding electrical power distribution (Figure 2). In turn, the electrical devices have been grouped in the main stages of the production process (reception, pressing, fermentation, filtration, storage, bottling and shipping, auxiliary activities and administration/office management), giving each device an operation time according to a productive process based on the data in energy audit.

Based on the energy audit carried out, series of energy saving measures (ESM) were identified for the analysis in the reference winery. For each ESM, a technical and economic feasibility study was conducted. To do this, it has been necessary to calculate potential energy savings and determine the investment and the lifespan of the measure. Various sources have been consulted, including the product catalogues of some commonly known manufacturers such as Daikin/CIAT/Lennox (chillers), Schneider (capacitor batteries and variable speed drives), ABB (electric motors), Ecoforest/Waterkotte (heat pumps), Enerlum (LED lighting), Circutor (energy analysers). There has also been the collaboration of engineering and consulting firms for the integration of a Building Management System (BMS).

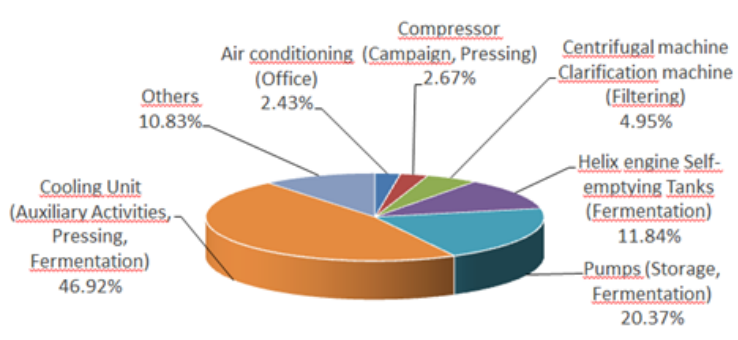

Figure 2. Distribution of energy consumption by technology in the reference winery (\% of total).

Distribuição do consumo de energia por tecnologia para uma adega representativa (\% do total).

The feasibility of measures was defined based on widely used profitability indicators: NPV (Net Present Value), IRR (Internal Rate of Return) and Payback. A discount rate of $4 \%$ (average rate of the last five years of the Spanish 10-year government bond) was used.

Under the baseline scenario, a sensitivity analysis was made, quantifying the profitability with changes in 
critical parameters, and determining the threshold of profitability, specifically for:

$\checkmark$ Changes in investment cost,

$\checkmark$ Changes in estimated saving,

$\checkmark$ Variations of the useful life of the equipment,

$\checkmark$ Variations of the discount rate, assuming a change in economic conditions that implied a change equivalent to that variation.

Sensitivity analysis allows one to extrapolate the results obtained in the reference winery to other scenarios, adapting the results to the specific characteristics of each winery.

\section{RESULTS AND DISCUSSION}

\section{Energy analysis of the current situation}

For the reference winery, data from energy audits has allowed one to characterise the energy consumption of the winery. Energy consumption has a high seasonality, with the highest consumption peaks in the months of August, September and October, coinciding with grape harvesting period (Figure 3).

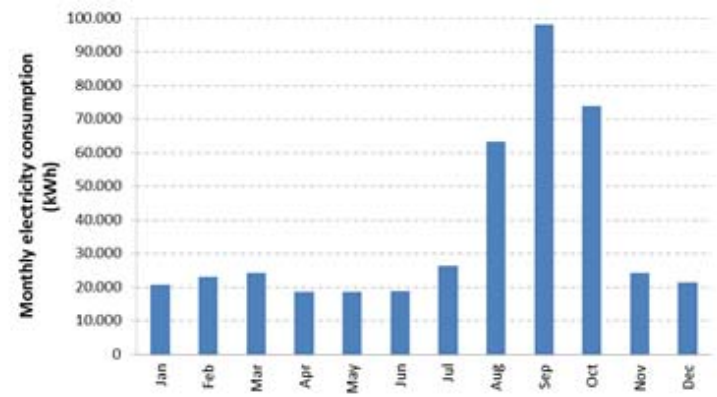

Figure 3. Monthly electricity consumption during a year in the reference winery.

Consumo de energia eléctrica ao longo do ano para uma adega representativa.

Energy consumption distribution (Figure 4) shows that the process involving the highest energy consumption is the fermentation followed by storage, bottling and shipping and pressing phases.

Within the production process, the equipment involving the highest consumption is the cooling equipment used in the fermentation process and pump/electric motors used in the phases of fermentation, storage, bottling and shipping (Figure 2).

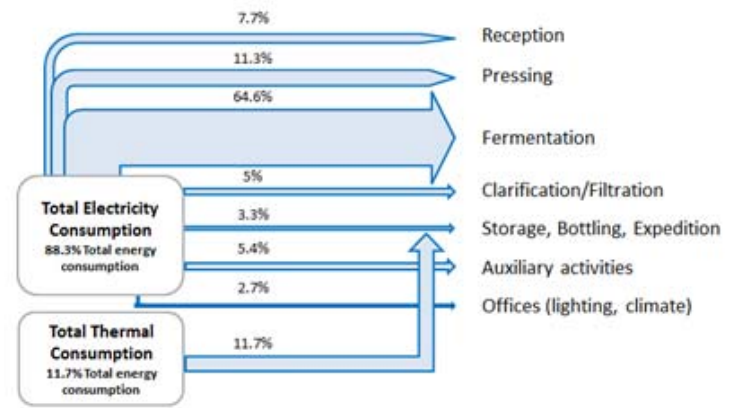

Figure 4. Energy balance (Sankey diagram).

Balanço de energia (diagrama Sankey).

\section{Proposal of energy efficiency measures}

Based on the energy audit, a series of energy saving measures that were studied in the reference winery have been identified, involving the introduction of new technologies, replacing equipment with more efficient and improving management and control. The measures studied are described below.

a) Measures that could generate significant savings by replacing key elements of the production process

ESM1. Fermentation chiller replacement.

The fermentation process is the one involving the highest electricity consumption in wine production, so it should be the first measured to study. The performance of an old cooling equipment (measured by the Energy Efficiency Ratio, EER), can be much lower than that of a modern one, so its replacement can generate large annual savings.

ESM2. Installing variable speed drives (VSD) in centrifugal pumps.

VSDs help to decrease power consumption in centrifugal pumps that are coupled, resulting in significant reductions in operating costs. A VSD is based on the rotational speed control of alternating current motors through the supply frequency control, allowing its soft start and stop.

ESM3. Replacing electric fermentation motors with others of a higher-efficiency.

The currently manufactured standard motors have a higher efficiency over engines from 20 years ago, but these are outweighed by the so-called high efficiency engines. The replacement of a motor in operation for a high-efficiency one is more attractive in those cases where the current one operates at low load factor and consequently, with low efficiency and low power factor; in this case the replacement should be evaluated with a high-efficiency motor of a lower 
power than the current one. By these criteria, the parameters substantially improve obtaining attractive energy and economic savings. It is also attractive from the operational point of view to do the replacement when the current motor operates at full capacity or at its service factor.

b) Measures that could generate less relevant savings in complementary processes to the production phase

ESM4. Replacing conventional lighting by LED lighting technology.

Power consumption for lighting is not one of the most important of the winery; however, replacing the existing lighting based on compact fluorescent, fluorescent lamps, mercury vapour and metal halide lamps by other equivalent equipment with LED technology can generate significant savings if usage time is high, or if their usage life is at their end and their luminous flux has decreased.

ESM5. Implementation of geothermal energy for air conditioning.

Geothermal heat pumps have a performance up to 5 times higher than that of the heating and sanitary hot water (SHW) traditional production based on fossil fuels or electricity. Their performances are typically higher than $400 \%$, so the savings that can be obtained are interesting, despite the higher cost of installation.

ESM6. Implementation of aerothermal air conditioning.

The installation of aerothermal units, based on heat pumps, allows the capture of the energy in the air for free and to use for heating or chilling an area and/or for the production of hot water needed in an installation. The aerothermal unit uses a heat exchanger of high efficiency to absorb heat from the air and transport it to the indoor unit at low temperature, minimising heat loss. The performances are somewhat lower than in geothermal systems, but the installation cost is also lower.

ESM7. Installation of capacitor batteries.

It arises not as a measure of energy saving but as a measure to reduce or eliminate the penalty in electricity bills for having an excess of reactive energy. Reactive power is caused by the characteristics of the receiving facility. Capacitor batteries save on the electricity bill compensating reactive power and preventing measuring equipment (meters) from recording the kVArh. c) Measures/Tools for efficient management of energy consumption

The savings deriving from these measures cannot be calculated by simply examining the cost of replacing equipment, but they certainly provide the base for efficient "energy management" of any asset. They are therefore measures or management tools that will generate savings for further information, knowledge and greater control. It is the foundation and one of the first steps in energy efficiency to be applied in any asset.

One should prioritise investment in energy analysers that manage the asset, as they will have a large impact. The same happens with the BMS which would be the "heart/brain" of the facility.

ESM8. Installing energy analysers for consumption monitoring by equipment and uses.

The energy and cost savings are not per unit itself, but for the management capacity it provides. The information provided by energy analysers can quickly detect anomalies and malfunctions of the electrical devices, identify equipment that could be changed by more efficient ones, assess changes of habits and processes (e.g. quantify the energy savings made by harvesting at night), reinforcing acquired habits that save time, among others.

Based on the experience of engineering and consulting firms with extensive experience in the industry, having knowledge about the consumption areas or processes of an installation allows for reductions of up to $30 \%$.

ESM9. Implementation of a Building Management System (BMS) as management and control system.

The new communication technologies allow the implementation of energy management systems and more sophisticated expert systems, which are able to manage large amounts of data and control the facilities. When a management system or an expert system is installed, the objective is to achieve greater efficiency in the facilities, save energy, increase comfort, reduce manpower (maintenance), reduce breakdowns and extend the lifespan of the equipment as main measures. These expert systems are able to control energy consumption by optimising the parameters so that minimal energy cost is obtained, and savings can reach $30 \%$.

The management system is usually based on a computer and management software. However, this tool requires an operator or person in charge to manage the energy process to achieve savings and improvements. 


\section{d) Other measures}

In addition to the above measures, there are other measures that do not require investment, such as good management practices (focused on the behaviour and habit of use), optimisation of power and the contracted electrical rate or negotiations of price of power supply with the distributors. Some of them do not involve reducing power consumption directly, but do reduce cost. However, these measures will not be analysed in this study.

\section{Assessment of energy efficiency measures}

For each proposal of ESM a technical and economic study has been made to determine its feasibility. Tables I and II summarise the main features of the proposals and profitability indicators achieved.

\section{TABLE I}

Main features of the current installation and energy efficiency measures analysed

Principais características da análise de instalação e medidas de eficiência energética

\begin{tabular}{|c|c|c|c|c|c|c|c|c|}
\hline & \multicolumn{3}{|c|}{ Current } & \multicolumn{5}{|c|}{ Proposal } \\
\hline & $\begin{array}{c}\text { Power } \\
\mathrm{kW}\end{array}$ & $\begin{array}{c}\text { Consumption } \\
\text { kWh/year }\end{array}$ & $\begin{array}{c}\text { Efficiency } \\
\text { or EER }\end{array}$ & $\begin{array}{c}\text { Power } \\
\mathrm{kW}\end{array}$ & $\begin{array}{c}\text { Consumption } \\
\text { kWh/year }\end{array}$ & $\begin{array}{c}\text { Efficiency } \\
\text { or EER } \\
\end{array}$ & $\begin{array}{c}\text { Investment } \\
€ \\
\end{array}$ & $\begin{array}{c}\text { Useful life } \\
\text { Years }\end{array}$ \\
\hline ESM1 & 105.0 & 115,937 & $3.1 / 2.9$ & 104.0 & 41,314 & $5.8 / 4.8$ & 35,200 & 20 \\
\hline ESM2 & 74.8 & 73,426 & & 45.4 & 44,577 & & 24,078 & 10 \\
\hline ESM3 & 99.3 & 109,728 & $85.8 \%$ & 94.0 & 103,794 & $93.6 \%$ & 14,977 & 20 \\
\hline ESM4 & 0.4 & 1,163 & & 0.1 & 543 & & 1,047 & 20 \\
\hline ESM5 & 5.0 & 8,150 & 2.5 & $3 / 12$ & 2,445 & 6.1 & 16,868 & 20 \\
\hline ESM6 & 5.0 & 8,150 & 2.5 & 6.0 & 5,705 & 3.7 & 9,750 & 20 \\
\hline ESM7 & 507.4 & 335,889 & & 0 & 0 & & 2,535 & 10 \\
\hline ESM8 & 507.4 & 335,889 & & 456.7 & 302,300 & & 26,626 & 12 \\
\hline ESM9 & 507.4 & 335,889 & & 431.3 & 285,505 & & 47,500 & 10 \\
\hline
\end{tabular}

\section{TABLE II}

Savings generated and profitability indicators of the energy efficiency measures analysed Poupanças geradas e indicadores de rentabilidade das medidas de eficiência energética

\begin{tabular}{|c|c|c|c|c|c|c|c|}
\hline & \multicolumn{4}{|c|}{ Savings } & \multirow{2}{*}{$\begin{array}{c}\text { Payback } \\
\text { years } \\
\end{array}$} & \multirow{2}{*}{$\begin{array}{c}\text { NPV } \\
€ \\
\end{array}$} & \multirow{2}{*}{$\begin{array}{c}\text { IRR } \\
\% \\
\end{array}$} \\
\hline & kWh/year & $€ /$ year & t CO2/year & $\%$ & & & \\
\hline ESM1 & 74,623 & 7,888 & 29.8 & $64 \%$ & 4.5 & 71,995 & $22 \%$ \\
\hline ESM2 & 28,849 & 3,049 & 11.5 & $39 \%$ & 7.9 & 17,364 & $11 \%$ \\
\hline ESM3 & 5,935 & 627 & 2.4 & $5 \%$ & 23.9 & $-6,452$ & $-2 \%$ \\
\hline ESM4 & 620 & 117 & 0.2 & $59 \%$ & 9.0 & $542 €$ & $9 \%$ \\
\hline ESM5 & 5,705 & 603 & 2.3 & $70 \%$ & 28 & $-8,673$ & $-3 \%$ \\
\hline ESM6 & 2,445 & 259 & 1 & $30 \%$ & 37.7 & $-6,238$ & $-5 \%$ \\
\hline ESM7 & 0 & 768 & 0 & $2 \%$ & 3.3 & 7,896 & $30 \%$ \\
\hline ESM8 & 33,589 & 3,550 & 13.4 & $10 \%$ & 7.5 & 21,624 & $12 \%$ \\
\hline ESM9 & 50,383 & 5,326 & 20.2 & $15 \%$ & 8.9 & 24,876 & $9 \%$ \\
\hline
\end{tabular}


ESM1. Fermentation chiller replacement.

In the case of the reference winery, using 10 year old cooling equipment with an estimated EER next to 3 as a starting point, and replacing the chiller with one of greater efficiency (EER of 4.82, according to manufacturer data). This represents an increase in the cooling efficiency coefficient of $64 \%$, generating annual savings in consumption of around 75,000 kWh (22\% of total annual electricity consumption). With these values, the payback period would be 4.5 years, which makes this measure attractive to undertake. This action would avoid emitting about $30 \mathrm{t} \mathrm{CO}_{2}$ per year.

ESM2. Installing variable speed drives in centrifugal pumps.

It is planned to incorporate variable speed drives in existing centrifugal pumps in the reception phase, fermentation and decanting. Assuming average potential savings near $39 \%$, this measure would mean annual savings in the reference winery of around $29,000 \mathrm{kWh} /$ year $(8.6 \%$ of total annual electricity consumption) with the investment having a payback period of 7.9 years. This action would prevent the emission of $11.5 \mathrm{t} \mathrm{CO}_{2}$ per year. In the event that a replacement pump for obsolescence arises, the new pumps should have already installed with the variable speed driver.

ESM3. Replacing fermentation electric motors with others with higher-efficiency.

It is proposed to replace the current motors, considered classification IE1 (standard efficiency) of an average efficiency of $85.8 \%$ and an average power of $99.33 \mathrm{~kW}$, for other motors classification IE4 (premium efficiency) of $93.6 \%$ and an average power of $93.96 \mathrm{~kW}$. Although this action would save electricity consumption of the engines of $5.41 \%$, approximately $6,000 \mathrm{kWh} /$ year (almost $2 \%$ of the total annual electricity consumption), the investment would not be profitable in the context studied. The payback would be greater than the useful life of the motors. This is due to the seasonality of production, with few operating hours per year. Therefore, this action would only be recommended to undertake in the renovation plan of the motors when their replacement for obsolescence is provided.

ESM4. Replacing conventional lighting by LED lighting technology.

Replacement of fluorescent lamps in the administration/office management and production facilities for LED lighting technology is proposed. In the reference winery, installing this type of technology means a reduction in lighting electricity consumption of $59 \%$, i.e. $0.2 \%$ savings on total consumption. The replacement of current lighting by LED lighting is an interesting measure to be implemented. In the reference winery the payback is 9 years but the investment in LED lighting could be presumed. The recommendation would be the replacement of current lighting by LED lighting technology directly, or replacement of the current lighting when they stop working. However, in other wineries, with high power lamps (such as mercury vapour lamps) and a greater number of operating hours, profitability could be much higher. In any case, it would be an interesting efficiency measure.

ESM5. Implementation of geothermal energy for air conditioning.

In the reference winery, they would only have to heat the office area, achieving savings around 5,705 $\mathrm{kWh} /$ year, i.e. a saving of $70 \%$ of electricity consumption (nearly $2 \%$ of total annual electricity consumption), and stop issuing $2.3 \mathrm{t} \mathrm{CO}_{2}$ per year. The payback is very high, mainly for the costs of drilling the terrain. The geo-thermal installation would not be profitable in the examined framework. It would be necessary to increase the hours of performance of the installation throughout the year so that the NPV was positive.

ESM6. Implementation of aerothermal air conditioning.

In the reference winery, savings would be obtained around 2,445 kWh/year, i.e. a saving of $30 \%$ of electricity consumption (almost $1 \%$ of the total annual electricity consumption), preventing the emission of $1 \mathrm{t} \mathrm{CO}_{2}$ per year. The payback would be higher than 10 years.

While geothermal energy uses the heat stored in the interior of the earth, constant in the first meters of the earth's crust; the aerotherm draws the outside air, so it is variable depending on the season of the year. For this, the expected savings are initially higher in geothermal energy than in aerotherm.

Overall for warm areas where the temperature demanded is not very high, such as $35^{\circ}$ necessary for area to be conditioning, the aerotherm is a good choice because saving is important and the cost is not very high. But in areas with increased demand and significant temperature variations between summer and winter (as would be the area of the reference winery), geothermal energy is the best option, the costs involved in drilling work by the savings generated they are amortised only by the constant temperature of the ground. 
However, both measures would be profitable from the current supply through fossil fuel boiler.

ESM7. Installation of capacitor batteries.

Analysing the data of monthly active and reactive power in the winery, it follows that the power factor of the installation is likely to be improved and not penalised by the power company. The installation of a capacitor battery for the reference winery would have a payback around 3 years and an annual cost savings of $800 €$ would be generated.

ESM8. Installing energy analysers.

For the reference winery, this action would entail savings in management of $10 \%$ of total consumption, about 33,600 kWh/year. It would avoid the emission of $13.4 \mathrm{t} \mathrm{CO}_{2}$ and the payback would be around 7.5 years.

ESM9. Implementation of a Building Management System (BMS) as management and control system.

For the reference winery, the implementation of a BMS would entail approximate savings of 50,400 $\mathrm{kWh} /$ year, representing a $15 \%$ savings on the total consumption. It would prevent the emission of $20 \mathrm{t}$
$\mathrm{CO}_{2}$ per year and the investment would be amortised in 9 years.

The technical-economic study of the ESM performed in the reference winery serves as an example of profitability that can be obtained in a real winery. However, a sensitivity analysis has been conducted that complements the study of the particular case, describing the changes in profitability to changes in key parameters, such as investment or annual savings generated (Figure 5). Sensitivity analysis also reveals the thresholds of profitability of different ESM.

Taking as an example the ESM1, the reduction of the annual cash flow should be greater than $70 \%$ so that the replacement of cooling equipment was not profitable (Figure 5). Therefore, even in cases where differences of the EER were much lower and annual savings generated were reduced by half, the investment would still be profitable. On the other hand, although the useful life of the equipment was reduced in 10 years for failure, equipment investment would have been profitable (Figure 5). Similarly, the new equipment would still be profitable even if its price was double.
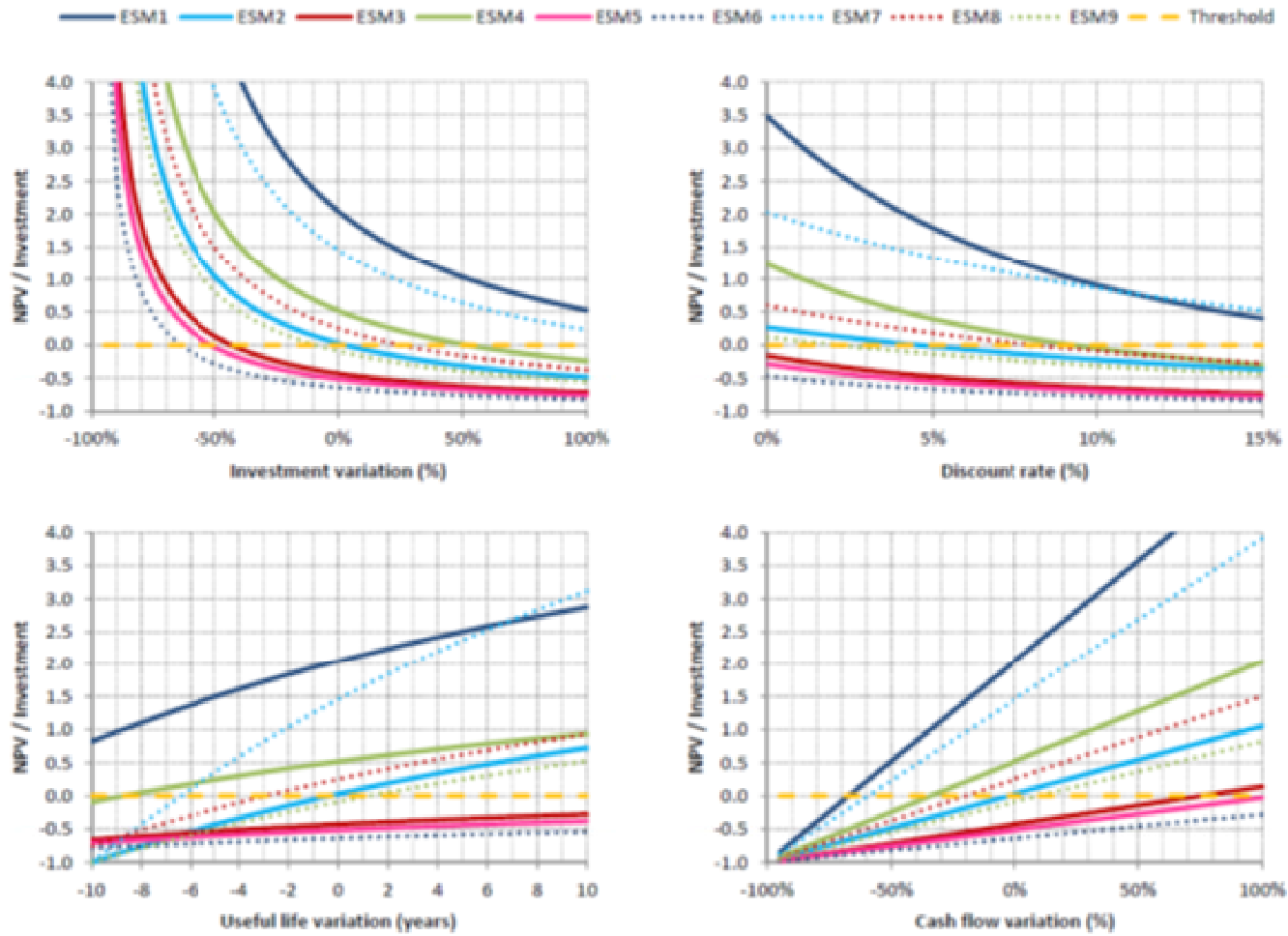

Figure 5. Variations in profitability (over NPV/investment) due to the change of the cost of the investment, the discount rate, the useful life and the cash flow.

Variações na rentabilidade (NPV/investimento) devido a alterações no investimento, na taxa de juro, na vida útil e no fluxo de caixa. 


\section{CONCLUSIONS}

The results show that in the wine making process there are a number of potential measures to be implemented that would help to attain a more efficient management of consumption. These measures generate a reduction of energy consumption and energy costs.

Generally, for any winery, the first steps to consider would be those that directly affect the production process, which is where the energy consumption is concentrated. Among them, the one that would generate greater savings would be replacing cooling equipment in the fermentation stage by other more efficient equipment, representing savings on the total consumption of approximately 20-25\%, with some acceptable payback periods between 4 and 5 years. Installing variable speed drives in centrifugal pumps is also an interesting measure. In this case, although the payback period of the investment is higher than the previous measure, around 8 years, it would save between $8-10 \%$ of the total electricity consumption. The replacement of electric motors in the fermentation phase with higher-efficiency is not profitable, since it works relatively few hours a year because of the seasonality of production. Obviously, if it is necessary to replace the equipment because of obsolescence or malfunction, the efficiency criteria should be taken into consideration when choosing a new motor.

Second, the implementation of management and control measures that would lead to a greater knowledge of the facilities (and, therefore, a greater capacity for decision making in terms of energy efficiency measures) are recommended. However, these measures would require human resources to manage the information, since by themselves they would not generate energy savings. On the one hand, the installation of energy analysers is recommended for monitoring consumption by equipment and applications to be aware of what each element and

\section{REFERENCES}

Alonso A.D., Northcote J., 2010. Small winery operators and business vision: A western Australian case. J. Wine Res., 21, 19-34.

Barbaresi A., Torreggiani D., Benni S., Tassinari P., 2014. Underground cellar thermal simulation: Definition of a method for modelling performance assessment based on experimental calibration. Energ. Buildings, 76, 363-372.

Benni S., Torreggiani D., Barbaresi A., Tassinari P., 2013. Thermal performance assessment for energy-efficient design of farm wineries. T. ASABE, 56, 1483-1491. process consumes: consumption patterns can be characterised; the equipment with greater consumption can be identified; a baseline having a history of consumption to detect deviations almost immediately can be defined. On the other hand, it is recommended the implementation of a Building Management System (BMS), capable of controlling the power consumption by optimising the parameters so that a minimum energy cost is obtained. As the automation and instrumentation is increasingly common in industries of various types, it is important to know how make use of these technologies as a tool to achieve greater energy efficiency. Paybacks of both measures are around 8-10 years.

Finally, complementary energy saving measures could be implemented in the production process. Although they would not be the most representative in term of energy consumption, they would help the overall objective of minimising and rationalising consumption. The implementation of geothermal and aerothermal systems for heating and air conditioning and the replacement of conventional lighting by another of LED technology in the different areas would be more interesting the longer as the operating hours are extended and the power level of the equipment in raised.

Although it has not been studied in detail herein, we recommend certain energy efficiency measures to be applied in any sector. The analysis of the implementation of best management practices, the optimisation of power and electricity tariff contracted once implemented energy saving measures and the review of the economic conditions of the electric supply contract are broadly applicable.

\section{ACKNOWLEDGMENTS}

This study was funded by the project TESLA (Transferring Energy Save Laid on Agroindustry) cofunded by the European Commission under the program Intelligent Energy-Europe.

Canas I., Mazarrón F.R., 2009. The effect of traditional wind vents called zarceras on the hygrothermal behaviour of underground wine cellars in Spain. Build. Environ., 44, 1818-1826.

CEEV, 2014. Comité Européen des Entreprises Vins. About the EU wine sector, 2014, fromhttp://www.ceev.eu/about-the-eu-winesector

Celorrio R., Blanco J., Martínez E., Jiménez E., Sáenz-Diez J.C., 2016. Determination of energy savings in alcoholic wine fermentation According to the IPMVP protocol. Am. J. Enol. Vitic., 67, 94-104.

Celorrio R., Martínez E., Sáenz-Diez J.C., Jiménez E., Blanco J., 2015. Methodology to decrease the energy demands in wine 
production using cold pre-fermentation. Comput. Electron. Agr., 117, $177-185$

CO2OP Project, 2011. Handbook of energy efficiency in wineries, 2011, from http://chil.es/agroindustria/group/eficienciaenergetica/document/manual-de-eficiencia-energetica-en-bodegas

Cyr D., Kushner J., Ogwang T., 2012. The size distribution of California's north coast wineries: 1984-2009. Int. J. Wine Bus. Res., 24, 6-18.

Forbes S.L., De Silva T.A., 2012. Analysis of environmental management systems in New Zealand wineries. Int. J. Wine Bus. Res., 24, 98-114.

Fuentes-Pila J., García J.L., 2014. Handbook: Efficient wineries TESLA project deliverable D.6.6: European Commission.http://teslaproject.chil.org/download-doc/62556

Gaspar P.D., Silva P.D., Nunes J., Andrade L.P., 2014. Characterization of the specific electrical energy consumption of agrifood industries in the Central Region of Portugal. Appl. Mech. Mater., 590, 878-882.

Hejiang S., Qingxia Y., 2014. Influence of infiltration on energy consumption of a winery building. Front. Energy, 8, 110-118.

Iannone R., Miranda S., Riemma S., De Marco I., 2016. Improving environmental performances in wine production by a life cycle assessment analysis. J .Clean. Prod., 111, 172-180.

Lijun W., 2014. Energy efficiency technologies for sustainable food processing. Energ. Effic., 7, 791-810.

Martinodotnez C.I.P., 2010. Analysis of energy efficiency development in the German and Colombian food industries. Int. J. Energ. Sec. Manage., 4, 113-136.

Mazarrón F.R., Canas I., 2008. Exponential sinusoidal model for predicting temperature inside underground wine cellars from a Spanish region. Energ. Buildings, 40, 1931-1940.

Mazarrón F.R., Canas I., 2009. Seasonal analysis of the thermal behaviour of traditional underground wine cellars in Spain. Renew. Energ., 34, 2484-2492.

Mazarrón F.R., Cid-Falceto J., Canas I., 2012b.Ground Thermal Inertia for Energy Efficient Building Design: A Case Study on Food Industry. Energies, 5, 227-242.

Mazarrón F.R, Cid-Falceto J, Canas-Guerrero I, 2012a. Assessment of aboveground winery buildings for the aging and conservation of wine. Appl. Eng. in Agric., 28, 903-910.

Mazarrón F.R., Lopez-Ocon E., Garcimartín M.A., Canas I., 2013. Assessment of basement constructions in the winery industry. Tunn. Undergr. Sp. Tech., 35, 200-206.

Miah J.H., Griffiths A., McNeill R., Poonaji I., Martin R., Morse S., Sadhukhan J., 2015. A small-scale transdisciplinary process to maximising the energy efficiency of food factories: insights and recommendations from the development of a novel heat integration framework. Sustain. Sci., 10, 621-637.

Neves P.L., Lebres C., Botelho G., Fonseca Ferreira N.M., 2013. Prototype to control alcoholic fermentation temperature in winemaking.Ciência Tec. Vitiv., 28, 71-76

Point E., Tyedmers P., Naugler C., 2012.Life cycle environmental impacts of wine production and consumption in Nova Scotia, Canada. J. Clean. Prod., 27, 11-20.

Pomarici E., Vecchio R., Mariani A., 2015. Wineries' Perception of Sustainability Costs and Benefits: An exploratory study in California. Sustainability, 7, 16164-16174.

Rodríguez-González O., Buckow R., Koutchma T., Balasubramaniam V.M., 2015. Energy requirements for alternative food processing technologies-principles, assumptions, and evaluation of efficiency. Compr. Rev. Food Sci. F., 14, 536-554.

Sellers-Rubio R., 2010. Evaluating the economic performance of Spanish wineries. Int. J. Wine Bus. Res., 22, 73-84.

Simon-Elorz K., Castillo-Valero J.S., García-Cortijo M.C., 2015. Economic performance and the crisis: Strategies adopted by the wineries of Castilla-La Mancha (Spain). Agribusiness, 31, 107-131.

Smyth M., Russell J., 2009. 'From graft to bottle'-Analysis of energy use in viticulture and wine production and the potential for solar renewable technologies. Renew. Sust. Energ. Rev., 13, 19851993.

TESLA project, Technical University of Madrid, 2014. Current process description: Wineries. European Commission, Intelligent energy Europe program. http://teslaproject.chil.me/downloaddoc/63247

TESLA project, Agro-food Cooperatives of Spain., 2015. Transfering Energy Save Laid on Agroindustry. European Commission, Intelligent Energy Europe Program. https://ec.europa.eu/energy/intelligent/projects/en/projects/tesla

Tinti F., Barbaresi A., Benni S., Torreggiani D., Bruno R., Tassinari P., 2014. Experimental analysis of shallow underground temperature for the assessment of energy efficiency potential of underground wine cellars. Energ. Buildings, 80, 451-460.

Tinti F., Barbaresi A., Benni S., Torreggiani D., Bruno R., Tassinari P., 2015. Experimental analysis of thermal interaction between wine cellar and underground. Energ. Buildings, 104, 275286.

Torreggiani D., Benni S., García A.I., Ayuga F., Tassinari P., 2014. Farm winery layout design: size analysis of base spatial units in an italian study area. T. ASABE, 57, 625-633.

Wei W., Mingxing H., Ceyue L., Yuan Z., 2014. The research of constant temperature and humidity air-conditioning system of underground cellar. Appl. Mech.. Mater., 672-674, 1722-1728. 